\title{
Social Factors Associated with Video Game Addiction Among Teenagers: School, Family and Peers
}

\author{
Yiyang Jin ${ }^{1, *, \dagger}$, Luyang Qin ${ }^{2, *},{ }^{*}$, Hanwen Zhang ${ }^{3, *}, \dagger$, Ruiyu Zhang ${ }^{4, *}, \dagger$

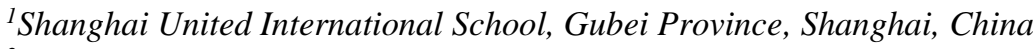 \\ ${ }^{2}$ Nanjing Foreign Language School, Nanjing, Jiangsu, China \\ ${ }^{3}$ Wuhan Maple Leaf International School, Wuhan, Hubei, China \\ ${ }^{4}$ Second Foreign Language School affiliated to Shanghai Normal University, Shanghai, China \\ *Corresponding author. Email: zhangruiyu1211@ gmail.com
}

These authors contributed equally.

\begin{abstract}
The 21st century has experienced a rapid advancement in technological. In the era of information overload and rapid technology growth, video game addiction has been in an increasing trend, especially among teenagers, which has raised many scholars' concern. This review paper would focus on the social factors associated with video game addiction among teenagers, from perspectives of school, family, and peers. Undeniably, video games could bring advantages to teenagers, as it offers those who are experiencing emotional or physical difficulties an escape from reality. However, video games have several undesirable consequences to teenagers, who tends to find themselves losing the ability of selfcontrol, time management, and concentration, traits that are essential for them to be successful in academic careers and adaptations to future life. It is attributed to multiple factors, and social factors are one of the most influential factors on teenagers. For teenagers, family has an essential influence on their understanding of the world and learning. School environment and school connectedness could also mitigate the effect of stressful life experience on video gaming addiction. Peers' gaming behaviour and self-satisfaction from others are other causes of the addiction. Based on analysing previous researches from the perspectives above, this paper offers theoretical support for the subsequent researches in this field.
\end{abstract}

Keywords: Video game addiction, Teenagers, Social factors, Family, School, Peers

\section{INTRODUCTION}

Psychologists and psychiatrists have defined addiction as a neuropsychiatric disorder characterized by a recurring desire to continue taking the drug despite harmful consequences [1]. While public may be familiar with drug addiction, non-substance addiction has also become a rising issue in modern society [2]. Game addiction is a relatively special kind of addictive behavior. The main symptom is that the individual is highly dependent on the game, and the patient is deeply addicted to the game world, forgetting that one has to face the reality, which seriously affects the normal life of the individual [3]. With the development of technology, video games have become more and more popular, and video game addiction has become a major part of game addiction. Video game addiction refers to a kind of addictive behavior in which Internet users are unstoppably and excessively addicted to online games for a long time and cannot extricate themselves from it, i.e., it brings physical, psychological and other effects to the users [4]. Video game addiction increases the risk of mood disorders, obsessive thoughts, and social problems; players report neglecting meals, school, and work; sleeping less; and experiencing tension with family members [5].

The study of video game addiction has become the most researched subfield in the field of cyber psychology contemporarily, along with the development of network and game technology and the increase of the population using it. Researchers have explored various aspects, including conceptual definition, pathological research, harmful effects and intervention methods. At present, when researchers investigate video game addiction, they generally focus on its causes and negative effects. Scholars mainly analyze the causes of game addiction from different theoretical perspectives with the 
combination of their own research fields. For example, some researchers, from the perspective of psychology, believes that the causes of teenagers' game addiction are the dependence of individuals to satisfy their needs of both absence and growth [6].

Teenagers are the largest group prone to addiction to games. According to the literature, the percentage of electronic game addiction among middle school students in a city was as high as $14.76 \%$. Video game addiction in a city is as high as $14.76 \%$, which is a rather alarming figure [7]. Some teenagers have been affected by the online world for a long time and are overly addicted to games. The impact of the online world and the excessive addiction to games have led to a significant drop in academic performance in school. This has a serious impact on their physical and mental development [8]. Among all the game gamers, teenagers are of particular concern because they are the primary target audience, and they are at the greatest risk for video gaming addiction [9]. Studies have also shown that other people's behavior can significantly affect one's own [3, 4]. Additionally, teenagers are more likely to engage in risky behaviors (including substance abuse) when they are with their peers than when they are alone [10-12].

In this review paper, we will seek potential social factors that contribute to video game addition. After defining video game addiction and demonstrating its impact, this review would focus on identifying social factors, from perspectives of family and school environments. Besides, the social relationships between teenagers.

\section{VIDEO GAME ADDICTION}

\subsection{The definition of video game addiction}

In the 2013 version of the American Psychiatric Association (APA)'s Diagnostic and Statistical Manual of Mental Disorders-5 (DSM-5), the third research supplement to the manual included video game addictions $[13,14]$. However, until today, researchers have not agreed on definitions of video game addiction.

According to the World Health Organization [15], video game addiction is classified as a mental health condition. It is defined in the 11 th revision of the International Classification of Disease (ICD-11) as a pattern of gaming behavior characterized by impaired control over gaming, lowering the priority of other subjects, e.g., academic performance and physiological needs. (WHO, Addictive behavior: Gaming disorder). According to Grifiths, video game addiction is a phenomenon of dependence on online games, which generally refers to the uncontrollable, repeated and prolonged playing of online games and addiction to them. It is a kind of online behavior that may cause individuals' obvious physical, psychological and social functions to be damaged [4]. The definition used by World Health Organization will be used in this essay because WHO is a credible organization, and is widely adopted and accepted by international communities and medical research institutes.

\subsection{The impacts of video game addiction}

Undeniably, playing video games moderately can have a beneficial effect on teenagers. According to previous studies, playing video games regularly could improve in mental rotation performance. Players could perform more accurately in short-term memory test of visual abilities. They could also make decisions about rotated objects more quickly [16]. Nevertheless, video game addiction could bring great harm to all aspects of teenagers' personal growth. At the physical level, prolonged eye fatigue causes vision loss, eye diseases, and weakened dark adaptability, while the body is in a state of long-term tension and exhaustion, which may cause disorders of the vegetative nerves, imbalance of hormone levels in the body, insomnia, headaches, decreased appetite, and gastrointestinal neurosis, etc. [17].

At the psychological level, teenagers are in a period of rapid and unstable physical and mental development, and their main task is the formation of self-identity, the development of real self-concept, and the formation of objective knowledge and evaluation of self, and self and others. However, addiction to online games hinders this process of self-identity development, i.e., the "ideal self" in the game cannot be integrated with the "real self" in reality, resulting in a long-term diffusion of identity and inability to know the self, self and others objectively [18]. In addition, the development of teenagers' imagination, creativity, and logical reasoning ability is affected by the activity they engage in. Since most online games involve violence, murder, and pornography, they provide an extremely negative role model for teenagers who are weak in discernment and immature in values [19]. Finally, the long-term concentration of time and energy on online games will inevitably lead to negligence in learning, resulting in the decline of learning performance [17].

\section{SOCIAL FACTORS RELATED TO VIDEO GAME ADDICTION}

In the millions of years of human evolution, many abilities have been shed, but the ability to socialize has remained unchanged. People either crave or reject, but most people have been forced to integrate socially [20]. People are herd animals, and the need for social interaction is as basic as the need for food and shelter. Each group has a social circle of its own, and friends would affect the level of entitlement people will reap. When there are no close people to cling to, the individual's "emotional loneliness" would rise. When individuals lack a sense of social integration or belonging 
to a community, "social loneliness" would rise. Either type of loneliness can lead to a subjective sense of unhappiness [21].

Game developers have grasped this human nature and integrated socialization into the game, making it easier for teenagers to establish social relationships in the game and increasing the possibility of teenage game addiction [22]

. For example, a series of MOBA games, led by "King of Glory", have promoted communication between players and set up a friend-adding system in the game, which is a kind of encouragement for socialization between players. On the one hand, players can establish new social relationships within the game, and they can also use the game to maintain existing relationships [21]. Therefore, after reviewing previous articles, we believe that it would be more appropriate to analyze the factors of video game addiction among teenagers from social perspectives: family, school and peers.

\subsection{Family environment}

The absence of a parent or one of the parents can lead to a lack of love, which further leads to a lack of emotions and abilities, e.g., empathy and the ability to learn. This lack of emotions and abilities can lead to a tendency for this group to seek the kind of love that has not been granted in the virtual world or to indulge in it to relieve their feelings of powerlessness [5].

\subsubsection{Over-expectations}

The high expectations and demands placed on children by parents at home can lead to children not being able to fulfil the high expectations set by their parents in a timely manner and choosing to find satisfaction in games that provide a quicker sense of achievement. Thus, it becomes dependent on games, which provides a quicker sense of achievement. Trauma is behind addictive behavior, i.e., the most important thing in dealing with addiction is dealing with past trauma and rebuilding real-life intimate relationships, especially with parents [7].

Many parents are reluctant to admit that something is wrong with their parenting style or family relationships. What is often heard is, "It's the game" or "It's the child". It is unfair to blame games for a child's addiction problems. In a good family atmosphere, games are often just a means for children to relax and have fun. It is not advisable to blame all problems on the child, and parents in families with parent-child relationship problems are often accustomed to scolding their children. They should generally be required to relinquish control. It is not the child who needs to relinquish control, but the parents, while, this is not easy. Children can become addicted to the game, and so can the controller who is addicted to control. Many parents will feel that once one lets go of their child they will lose control even more, but if the parent does not let go, the child will continue to go to the virtual world in search of freedom [3].

\subsubsection{Parent-child relationship}

For every child, their understanding of the world and learning begins through family. Consequently, when studying the social factors of video game addiction, family is an essential aspect. According to Jeong's research, the way parents educate and the general activities parents engage in are directly and negatively correlated with game addiction [3]. The more contact parents have with their children in their daily lives, the less likely their children are to become addicted to games. When children have no way to communicate with their parents frequently in daily life, and when they choose to communicate with their classmates, teachers and other social relationships, the possibility of developing game addiction rises sharply.

There is no correlation between parents playing games with their children and game addiction. Parents playing games with their children may be a positive mediating role in preventing children from being negatively affected by games [23]. Based on the understanding of ecosystem theory, they argue that family is the earliest and most intimate environment of individual contact, parental behavior is closely related to adolescent development. According to the theory of self-determination, parental psychological control and parental autonomy support, as two different ways of parental education, can reveal the influence of adolescent problem behavior development. The different relationships between parents and children will lead parents to use different ways of education, and children will directly result in the possibility of game addiction in their children. To a large extent, parents' parenting style is closely related to their children's spontaneous emotion, independent thinking and choice. In this way, educational methods can be roughly divided into two categories: parental control and parental independent support. Parental control is defined as a parent's aggressive control over an adolescent's feelings and thoughts through verbal or non-verbal means. This will greatly undermine their development of autonomy. Parental independent support means that parents accept their children's emotions, thoughts and reactions, and support their independent choice and self-determination. When such behavior can meet the basic psychological needs of children, it will promote the development of children's mental health. In addition, parents' educational behavior cannot meet the psychological needs of children, which will lead to children's maladjustment, e.g., game addiction.

Video game addiction is strongly linked to both children and parents. Parents respect their children's selfchoice and spontaneous emotions. In the growth process of children, they do not use the method of negative education to force children not to play games. Parents can 
try to relax themselves after exhausting work with children. This helps parents and children to bond and see the game from the same perspective, which could also reduce the likelihood of teenagers' developing video game addiction.

\subsection{School environment}

The school environment would include organizational structure, characteristics of individuals, and the norms of the school [24]. School environment is classified into two dimensions: protective and risky school environments. Protective environment is defined as the positive school atmosphere that has positive effect on students' behaviors, thoughts and feelings. It also includes positive interactions among students and teachers and following the school rules. On the other hand, the risky environment refers to a school atmosphere that most students show delinquent behaviors and break school rules. The researchers concluded that in the school-level, grade, negative and positive school environment would significantly predict game addition [8]. Based on conducting multilevel analyses, participants who belonged to schools with low scores on risky school environment reported higher scores of game addiction. In contrast, participants with lower scores of protective school environment scored lower on game addiction. As a result, it could be interpreted that there was significant association between game addiction and school environment.

Research also supports the idea that school connectedness would mediate the relationship between stressful life experience and online gaming addiction. School connectedness is students' perception that they are accepted and respected by other important people like teachers or in important places like classrooms in their school. A high level of perceived connectedness with school can effectively reduce the time spent on online gaming among adolescents at risk of video gaming addiction. By testing a moderated mediation model, they found that a higher level of school connectedness was associated with a lower level of video gaming addiction. More importantly, school connectedness mitigated the direct effect of stressful life experience on video gaming addiction, which suggests that school connectedness is an important bridge in the process of stressful life experience leading to video game addiction [4]. When a student is feeling stress from their life experiences, e.g., failing an important test, one is more likely to turn to online games for support. In addition, students are likely to become more detached from school because of these stressors, making them more vulnerable to online gaming addiction [25].

\subsection{Peers}

\subsubsection{Catering to peers and seeking friendship}

The peer effect refers to the fact that the utility of an individual adopting a certain behavior is affected by whether a peer adopts that behavior or not [26]. The peer effect in video games is mainly manifested in the peer's influence on teenagers', who have just broken through the narrow social circle of their families and open up the territory on campus, pulling in peers to become playmates. The gaming behavior of peers has a direct or indirect impact on that of teenagers [27].

Catering to peers and seeking friendship are deepseated reasons why teenagers play video games. McClure $\operatorname{Han}(2000 / 1964)$ [28] argues that video games, as a medium of communication, are equally an extension of the human being. Games is a medium for interpersonal interaction and an extension of group perception. There is no doubt that digital media has rewritten the way people socialize today. Nevertheless, people are also enduring the online social pressure that it brings simultaneously. Some respondents play video games for social interaction. They want to have something in common with their peers, or to build friendships by playing video games.

\subsubsection{Self-satisfaction and recognition from others}

According to Jeong and Kim [3], low levels of selfconfidence and self-efficacy are positively correlated with the likelihood of getting addicted to video games. Bandura defines self-efficacy as "the conviction that one can successfully execute the behavior required to produce the outcomes," meaning that people with low self-efficacy might not be able to maintain social relationships successfully [11]. Human beings with low self-confidence or self-efficacy seldom engage in social activities, or have less opportunities of engaging in such activities, due to their negative perceptions of their competence in sociability. However, social relationships are indeed an indispensable psychological desire for most human beings, therefore, people with low self-confidence or selfefficacy need to look for an alternative to fulfill their desire.

The sense of belonging and identity conferred by peers motivates teenagers to learn to accept and imitate the lifestyles and values of their peers around them, which includes mobile game use behavior. Nowadays, teenagers live in a highly mediated society, where the ease of use of cell the Internet has become the "strongest auxiliary" factor for video game addiction. In addition, teenagers are quietly drawn into the whirlpool of addiction while gaining friendship, identity, and self-satisfaction as they work their way up through the game world with their peers [27]. 


\section{CONCLUSION}

Accessibility to internet has increased over the $21^{\text {st }}$ century, traits such as concentration, self-control and other natural traits are becoming a luxury and scarcer in an era of information overload. There is a lot of opportunity waste caused by multi-tasking and forms of digital addictions, e.g., video game addictions. More and more people, especially teenagers, are drawn to video games. Additionally, this forms a bandwagon effect where teenagers that do not wish to play video games are incentivized to play in need of social connections. Nowadays, the impact of society on the development of teenagers is becoming stronger. The education of families, the behavior of peers, and the guidance of schools all directly or indirectly affect the addictive behavior of teenagers. Analyzing adolescent video game addiction from a social perspective can provide a clearer understanding of one of the main causes that constitute to the addiction, and facilitate subsequent research and solution development.

The absence of a parent and the high expectations placed on children by parents can lead to children choosing to find satisfaction in games that provide a quicker sense of achievement, i.e., increase the possibility of video game addiction. In addition, there was a significant association between video game addiction and school environment, as teenagers among protective school environment scored lower on game addiction. Moreover, catering to peers and seeking friendship are also the factors that could be associated with video game addiction, along with self-satisfaction from others.

Based on analyzing the social factors associated with video game addiction, this paper can provide theoretical support for the subsequent measures against game addiction. This issue has also received the attention of psychologists and educationalists. One of the solutions to prevent video game addiction and disorder is to focus on factors that could be influenced through awareness. Parents' and schools' attitudes and peers' behaviors on some extent could determine whether teenagers would pursue what they are passionate about in the real world, instead of escaping to the virtual world. Overall, the best way to prevent addiction is to be more caring and pay may attention to teenagers' mental health. Parents and school should aim to respect teenagers' and encourage them to pursue something they truly love other than video games. Future researchers can build on our review to conduct further research on each sub-section. Researchers could delve into the effects of family parenting styles on adolescent addictive behaviors, the effects of different gaming behaviors of peers, the effects of school rules and regulations on adolescents' after-school gaming time, etc. Overall, these results shed light on the causes of teenagers' video game addiction and provide theoretical support for its prevention measures.

\section{REFERENCES}

[1] Ar Rosyid, H., Prawidya, D. M., Amalia, A., Fajariani, E., Adhilaga, H., \&amp; Shi, P. , The online game addiction, psychology and interpersonal relationship of the engineering students. Bulletin of Social Informatics Theory and Application, 2019 , 3(2), 75-79. https://doi.org/10.31763/businta.v3i2.88.

[2] Chang, E., \&amp; Kim, B. , School and individual factors on game addiction: A multilevel analysis. International Journal of Psychology, 2019 , 55(5), 822-831. https://doi.org/10.1002/ijop.12645.

[3] Jeong, E.J., \&amp; Kim, D. H., Social activities, Self-efficacy, Game attitudes, and game addiction. Cyberpsychology, Behavior, and Social Networking, 2011 14(4), 213-221. https://doi.org/10.1089/cyber.2009.0289.

[4] Wei, C., Yu, C., \&amp; Zhang, W. , Children's stressful life experience, school connectedness, and online gaming addiction moderated by gratitude. Social Behavior and Personality: an International Journal, 2019 , 47(12), 1-11. https://doi.org/10.2224/sbp.7942.

[5] Baoyang, W., (thesis). Case Intervention Study on Behavior Deviation of Minor Children from Singleparent Families. Retrieved from https://kns.cnki.net/kcms/detail/detail.aspx?dbcode $=C M F D \&$ dbname $=C M F D T E M P \&$ filename $=10216$ 09326.nh\&v=XgtDYuv3oFQVU2gPK6LH\%25mmd 2BVW9GKK83vaf\%25mmd2Fj6xZVZJnTjERXsl9Iw WO\%25mmd2BoqAOE9AXzL.

[6] Zhongxiao, S., An Integrative Perspective on Adolescent Internet Dependence: The Interaction of Intrinsic Needs and Family Environment. https://doi.org/10.19738/j.cnki.psy.2021.16.105.

[7] Shilan, C., Psychologist Shen Jiahong: Game addiction is a problem in family relationships. other. http://health.people.com.cn/n1/2018/0629/c14739. 30094886.html.

[8] Chang, E., \&amp; Kim, B. (2019). , School and individual factors on game addiction: A multilevel analysis. International Journal of Psychology, 55(5), 822-831. https://doi.org/10.1002/ijop.12645.

[9] Young, K., Understanding Online Gaming Addiction and Treatment Issues for Adolescent . The American Journal of Family Therapy, 37: 355 - 372 . .

[10] Li, D., Zhou, Y., Li, X., \& Zhou, Z. (2016). , Perceived school climate and adolescent internet 
addiction: The mediating role of deviant peer affiliation and the moderating role of effortful control. Computers in Human Behavior, 60, 54-61. https://doi.org/10.1016/j.chb.2016.02.015.

[11] Bandura, A., Self-efficacy: Toward a unifying theory of behavioral change. Psychological Review, 84(2), $191-215$. https://doi.org/10.1037/0033$295 x \cdot 84.2 .191$

[12] Goldstein RZ, V.N., Drug addiction and its underlying neurobiological basis: neuroimaging evidence for the involvement of the frontal cortex. Am J Psychiatry 159:1642-1653.

[13] Zou, Z., Wang, H., d'Oleire Uquillas, F., Wang, X., Ding, J., \&amp; Chen, H. (2017). , Definition of substance and non-substance addiction. Advances in Experimental Medicine and Biology, 21-41. https://doi.org/10.1007/978-981-10-5562-1_2.

[14] Chao, N. P. (2015). Wangluoyouxi yu qingshaonian de ziworentong - cong qianyufen wenjuan kan wang luoyouxi dui qingshaonian fazhan de yingxiang [Online games and teenagers' self-identity-The influence of online games on Teenagers' development from more than 1000 questionnaires]. Beijing: Zhongguo kexue shehuibao http://www.cssn.cn/skjj/skjj_jjgl/skjj_jjxm/201512/t 20151223_2795340.shtml.

[15] W.H.O.(n.d.). Addictive behaviours: Gaming disorder. World Health Organization. https://www.who.int/news-room/q-adetail/addictive-behaviours-gaming-disorder. .

[16] Boot, W.R., Kramer, A. F., Simons, D. J., Fabiani, M., \&amp; Gratton, G. (2008). The effects of video game playing on attention, memory, and executive control. Acta Psychologica, 129(3), 387-398. https://doi.org/10.1016/j.actpsy.2008.09.005.

[17] Tao, X. L. (2016). Lun zhongxuesheng wangluoyouxi chengyin de chengyin yu yufang [Study on the causes and prevention of middle school students' online game addiction]. Jiaoyu Xiandaihua, 21: 100-101.

[18] Liu, D. H., Peng, X. S., \& Xie, X. Z. (2014). Zuowei buchangjizhi de youxichengmi-qingshaonian youxichengmi de jiatingyinsu [Game addiction as a compensation mechanism:A brief study on the family factors of game addiction among the youth]. Guanggao Daguan, 3:18-27.
[19] Liu, Y. N., Hu, Y., \& Guo, H. (2014). Lun wangluoyouxi dui qingshaonian fanzui de yingxiang [The Influence of Online Games on Juvenile Crime]. Dongbei Shida Xuebao (Zhexue Shehui Kexueban),267(1):29-34.

[20] Aronson, E., Wilson, T. D., \& Sommers, S. R. (2021)., Social psychology. Pearson. .

[21] David, M., Social psychology. David Myers.

[22] Zihan, J., A study on the relationship needs of college students in social network games - taking MOBA hand game "Honor of Kings" as an example. .

[23] deng, 1., liu, X., tang, y. and li, p., 2021. , Parental Psychological Control, autonomous support and Adolescent Online game addiction: The Mediating role of impulsiveness. Parental psychological control; Independent parental support; Online game addiction; Impulse;. Faculty of Education, Beijing Normal University.

[24] Anderson, C.S., The search for school climate: A review of the research. Review of Educational Research, 52(3),368-420.

[25] Yu, C., Li, X., \&amp; Zhang, W. (2015), Predicting adolescent Problematic online game use from teacher autonomy support, basic psychological Needs satisfaction, and School ENGAGEMENT: A 2-Year longitudinal study. Cyberpsychology, Behavior, and Social Networking, 18(4), 228-233. https://doi.org/10.1089/cyber.2014.0385.

[26] Du, Y. H., \& Yuan, Y. Z. (2016). Jiaoyu zhong de tongbanxiaoying yanjiushuping [Review of peer effects research in education: concept, model and method]. Jiaoyu Jingji Pinlun, 1(3):77-91.

[27] Zhao, M. D., \& Li, L. (2020). Youxi “youling” weihe ruyingsuixing_zhongxiaoxuesheng shoujiyouxichengyin de zhixingyanjiu [Why does the game "ghost" follow?-A qualitative study on mobile game addiction of primary and middle school students]. Xinwen Jizhe, 2020,7:46-58.

[28] Marshall McLuhan, Understanding Media:The Extensions of Man, ( 2000/1964 ) . 